\title{
Malaria parasite prevalence and Haematological parameters in HIV seropositive patients attending the regional hospital Limbe, Cameroon: a hospital-based cross-sectional study
}

\author{
Sorelle Mekachie Sandie ${ }^{1 *}$ (D), Irene Ule Ngole Sumbele ${ }^{1}$, Martin Mih Tasah ${ }^{1}$ and Helen Kuokuo Kimbi ${ }^{1,2}$
}

\begin{abstract}
Background: Malaria and the human immunodeficiency virus (HIV) infection constitute public health problems in Cameroon including the South West Region (SWR). This study determined the prevalence of malaria parasites and haematological abnormalities in HIV positive patients in Limbe, Cameroon from April-July 2014.

Methods: The study was cross-sectional and involved 411 participants who were administered structured questionnaires to record socio-demographic and clinical data. Three hundred and nine (309) HIV positive patients and one hundred and two (102) HIV negative individuals were examined clinically and venous blood collected for malaria parasite detection, HIV infection diagnosis and full blood count analysis.

Results: Overall malaria parasite prevalence was $14.1 \%(58 / 411)$. This prevalence was significantly higher $(P<0.001)$ in the HIV negative participants $(33.3 \%, 34 / 102)$ compared to the HIV positive patients $(7.8 \%, 24 / 309)$. Amongst HIV positive participants, malaria parasite prevalence was significantly higher in female patients $(P=0.003)$, febrile patients $(P<0.001)$, anaemic patients $(P=0.015)$ and in patients who were not on antiretroviral treatment (ART) $(P=0.03)$ when compared with their respective counterparts. Among the HIV negative group, though not significant, malaria parasite prevalence was higher in females, febrile and anaemic patients when compared with their respective counterparts. Overall anaemia prevalence was $52.1 \%(214 / 309)$ and was significantly higher $(P=0.004)$ in HIV positive patients $(56 \%, 173)$ than in HIV negative participants $(40.2 \%, 41)$. Malaria/HIV co-infected patients had a significantly lower mean value of Hb $(P=0.002)$, RBC $(P=0.002)$ and Hct $(P=0.001)$ when compared with HIV-infected patients.

Conclusion: HIV negative participants had a higher prevalence of malaria parasites than their HIV positive counterparts. Anaemia prevalence was higher in HIV positive patients than in HIV negative participants. Malaria/HIV co-infected patients presented with more red blood cell abnormalities than HIV-infected patients.
\end{abstract}

Keywords: Malaria, Anaemia, Haematological parameters, HIV, Cameroon

\footnotetext{
* Correspondence: sandiesorelle2@gmail.com

'Department of Zoology and Animal Physiology, University of Buea, Buea,

Cameroon

Full list of author information is available at the end of the article
}

(c) The Author(s). 2019 Open Access This article is distributed under the terms of the Creative Commons Attribution 4.0 International License (http://creativecommons.org/licenses/by/4.0/), which permits unrestricted use, distribution, and reproduction in any medium, provided you give appropriate credit to the original author(s) and the source, provide a link to the Creative Commons license, and indicate if changes were made. The Creative Commons Public Domain Dedication waiver (http://creativecommons.org/publicdomain/zero/1.0/) applies to the data made available in this article, unless otherwise stated. 


\section{Background}

Malaria remains one of the most lethal human parasitic infections of our time with about 219 million cases and an estimated 435,000 malaria deaths recorded in 2017 [1]. Malaria is endemic in the 10 regions of Cameroon with an estimated prevalence of $29 \%$ [2]. The last decade has witnessed a massive scale up of malaria prevention efforts that have led to a significant reduction in malaria prevalence. HIV/AIDS infection further aggravates the morbidity in patients that are co-infected with malaria. The Cameroon government's efforts to increase HIV infected patients' access to anti-retroviral therapy (ART) is working, though not up to expectations. From 2012 to 2013, the treatment coverage rate ART increased from 20.5 to $26 \%$ [3]. ART slows the disease progression by preventing viral replication thereby decreasing the amount of virus in an HIV infected patient's blood, that is, the viral load. In areas with stable malaria, HIV increases the risk of malaria infection and clinical malaria in adults, especially in those with advanced immunosuppression. Some ARTs are known to possess antimalarial properties, and some could act together with antimalarials against P. falciparum $[4,5]$. Daily treatment with cotrimozaxole and ARTs have been associated with reduced prevalence of clinical malaria [6] and some protease inhibitors have specific antimalarial effects though the clinical relevance has not yet been established [7].

UNAIDS reported Sub-Saharan Africa in 2017 as the most severely affected region, with nearly 1 in every 25 adults (4.1\%) living with HIV and accounting for nearly 2-thirds of the people living with HIV worldwide [8]. Reports from UNAIDS (2014) revealed that just 15 countries in the world (including Nigeria, South Africa, Uganda and Cameroon) account for more than $75 \%$ of the 2.1 million new HIV infections that occurred in 2015 [9]. According to the National AIDS Control Committee/Central Technical Group [3], there are 141 new HIV infections per day in Cameroon, which means six newly infected persons each hour, daily.

The National Institute of Statistics in collaboration with the Ministry of Public Health reported the South West Region as one of the regions with highest malaria and HIV prevalence; approximately 40 and $7.2 \%$, respectively [3]. This is mostly due to the fact that the region is located in the tropical rain forest area and the majority of its population is made up of youths who are the most vulnerable group exposed to HIV. These two infections thus overlap in Southwest Cameroon and Limbe in particular [10]. The prevalence of Plasmodium/HIV co-infection in Cameroon varies from one region to the other; ranging from $2.24 \%$ in Bamenda [11] to $29.5 \%$ in Douala [12].

Both malaria and HIV lead to haematological abnormalities in the affected patients. The severity of haematological disease caused by Plasmodium especially $P$. falciparum is related to the ability of the parasites to invade and grow in different red cell populations as well as the intrinsic growth rate of the parasite [13]. Anaemia, leucopaenia and thrombocytopaenia are the most common haematological abnormalities resulting from both malaria and HIV infections especially in febrile patients $[14,15]$. Leucocytosis has been associated with severe malaria [16] while leucopaenia is an abnormal condition commonly found in HIV patients [15]. The use of anti-retrovirals could positively or negatively affect these disorders. In both anti-retroviral-treated and untreated individuals, several types of haematological abnormalities are common [17]. Considering the enormous impact of these diseases on each other in the affected individuals, it is necessary to constantly generate epidemiological data on them in different settings in order to ascertain the likely changes in these parameters. The objectives of this study were to determine the prevalence of malaria parasites and malaria/HIV co-infections as well as to assess the variation in haematological parameters in malaria infected patients and HIV/malaria coinfected patients attending the Regional Hospital Limbe.

\section{Methods}

\section{Study area}

The study was carried out in the Regional Hospital Limbe (RHL), Fako Division, South West Region of Cameroon. Limbe is a coastal town situated at the foot of Mount Cameroon and opens the South West Region to the rest of the world through the Atlantic Ocean. It covers an area of $185 \mathrm{~km}^{2}$ and as of 2014 had a population of 84 , 500 inhabitants [18]. Its climate is typically equatorial with annual rainfall exceeding $4000 \mathrm{~mm}$, temperatures ranging from $23^{\circ} \mathrm{C}$ to $32{ }^{\circ} \mathrm{C}$ and $80 \%$ relative humidity as reported by the Cameroon Development Corporation. Limbe is characterised by two distinct seasons; a rainy season running from mid-March to October and a dry season running from November to mid-March.

\section{Study population}

The study participants included HIV positive patients registered at the Voluntary Counselling Testing and Treatment Centre of the RHL and presumed HIV negative individuals presenting themselves at the Out Patient Department of the hospital for consultation during the study period. Participants were recruited irrespective of their age, sex, marital status, level of education, and with or without malaria-related signs and symptoms. Only those who gave their consent for blood collection and answered the questionnaire were enrolled in the study.

\section{Study design}

This cross-sectional study was conducted from MarchJune, 2014. An information sheet and a brief talk were 
given to the participants, explaining the objectives and benefits of the study. Participants were then invited to participate in the study by signing an informed consent form. In the case of children ( $\leq 16$ years) their parents signed a proxy consent form on their behalf. Before sample collection, a clinical examination was carried out followed by the administration of structured questionnaires to the participants. HIV-sero-negative individuals were persons at the hospital Out Patient Department who consented to be screened for HIV during the process and who tested negative for HIV.

The sample size was determined using the formula $\mathrm{n}=\mathrm{Z}^{2} \mathrm{pq} / \mathrm{d}^{2}$ [19] where $\mathrm{n}$ represented the sample size evaluated, $\mathrm{Z}$ was 1.96 , which is the standard normal deviate (for the $95 \%$ confidence interval, CI), p was 58.9 and $51.1 \%$ [10], the malaria prevalence in HIV patients on ART and those not on ARV, respectively, q was 1-p and $d$ was 0.05 . The optimum sample size calculated was $n=380$.

\section{Questionnaire}

A pre-tested structured questionnaire was administered to all the consented participants enrolled in the study to obtain socio-demographic data such as age, sex, level of education, marital status; while clinical data such as HIV status, ART usage, duration on treatment were collected from each patient's file at the HIV centre. The questionnaire also assessed the utilization of insecticide-treated nets and insecticide residual spray as preventive methods against malaria. An additional file shows the questionnaire used in detail (see Additional file 1).

\section{Laboratory procedure}

Before blood sample collection, a participant's axillary temperature was recorded using a digital thermometer. Fever was defined as temperature $\geq 37.5^{\circ} \mathrm{C}$. Under sterile conditions, a vacuum holder and vacutainer needle were used to collect $4 \mathrm{~mL}$ of venous blood into 2 well-labelled ethylenediaminetetraacetate (EDTA) tubes for each participant. A portion of the blood was used to prepare thick and thin blood films. The blood in one of the tubes was used for HIV rapid test (in the case of presumed HIV negative participants) and to conduct full blood count. Plasma was separated from the other portion of the blood, stored in an ice-filled cooler and transported to the Malaria Research Laboratory of the University of Buea for use in the HIV BISPOT assay. The prepared thin and thick blood films were Giemsa-stained and observed under the microscope following standard procedures [20] by two qualified microscopists. A complete blood count including values for white blood cell (WBC), red blood cell (RBC) and platelet counts, haemoglobin concentration $(\mathrm{Hb})$, haematocrit (Hct), mean corpuscular volume (MCV), mean corpuscular haemoglobin $(\mathrm{MCH})$, mean corpuscular haemoglobin concentration (MCHC), mean platelet volume (MPV), red cell distribution width (RDW), platelet distribution width (PDW), red blood cell distribution width coefficient of variation (RDW-CV), and red blood cell distribution width standard deviation (RDW-SD) was obtained using the URIT-3300 automated haematology analyser (URIT Medical Electronic CO., LTD. Jiuhua Road, Gungxi, China), following the manufacturer's instructions. Anaemia was defined as $\mathrm{Hb}<11.0 \mathrm{~g} / \mathrm{dL}$ and further classified as described by Cheesbrough (2009) as severe $(\mathrm{Hb}<7 \mathrm{~g} / \mathrm{dl})$, moderate $(\mathrm{Hb}$ between $7.0 \mathrm{~g} / \mathrm{dl}$ and $10.0 \mathrm{~g} / \mathrm{dl})$ and mild $(>10.0 \mathrm{~g} / \mathrm{dl}$ and $<11 \mathrm{~g} / \mathrm{dl})[20,21]$.

\section{HIV diagnosis}

The Determine Rapid Test Kit (Abott Laboratories, CO., Ltd. Minato-Ku, Tokyo Japan) was used to test the supposed HIV negative subjects for HIV-1. Test results were read after $15 \mathrm{~min}$ from corresponding colour changes on the strip according to the manufacturer's instructions.

All HIV positive results by the test kit were confirmed using the HIV-1 and 2 BISPOT assay (ORGENICS, Yavne, Israel). After bringing all components of the test kit and plasma samples to room temperature, $50 \mu \mathrm{L}$ of each specimen and controls was dispensed into separate wells of row A of the developing plate and gently mixed. The comb was then introduced into the wells of row A and incubated for $10 \mathrm{~min}$. The comb was later introduced into other wells serially with incubation and results were read by recognition of black dots on the comb teeth.

\section{Determination of CD4 T cell count}

Ten $(10) \mu \mathrm{L}$ of Guava Auto CD4/CD4\% antibody cocktail was placed into a $1.5 \mathrm{~mL}$ sample tube labelled with the patient's serial number. A reverse pipette of $10 \mu \mathrm{L}$ of whole blood (from the purple-top EDTA) was added onto the bottom of each tube containing the antibody cocktail. The tubes were vortexed immediately. The mixture was then incubated for $30 \mathrm{~min}$ at room temperature in the dark. Taking one tube at a time, $380 \mu \mathrm{L}$ Guava $1 \mathrm{X}$ lysing solution was added into it and then the mixture vortexed immediately. The mixture was incubated again in the dark at room temperature for $15 \mathrm{~min}$. Then each sample was acquired on a Guava PCA instrument with the Guava Auto CD4/CD4\% software module and the $\mathrm{CD} 4^{+} \mathrm{T}$-cell reading was recorded. $\mathrm{CD} 4^{+} \mathrm{T}$-cell counts were categorized as low or advanced stage $(<200 / \mu \mathrm{L})$, moderate or chronic stage $(200-499 / \mu \mathrm{L})$ and high or asymptomatic stage $(\geq 500 / \mu \mathrm{L})[12]$.

\section{Statistical analysis}

The data obtained was Haematol using the IBM Statistical package for the Social Science (SPSS) version 20.0 software (IBM-SPSS Inc., Illinois, USA). Data was summarized into 
means and standard deviation (SD) and percentages were used in the evaluation of the descriptive statistics. The significance of differences in prevalence were explored using Pearson's Chi-square or Fisher's Exact test while Analysis of Variance (ANOVA), Kruskal-Wallis test or Student's t test were used to assess difference in group means. Statistical significance was set at $P<0.05$.

\section{Results}

\section{Characteristics of the study population}

A total of 411 participants (309 HIV positive patients and 102 HIV negative patients) with a median age of 37 (range 1-72) years participated in the study. The study population consisted of $299(72.7 \%)$ females and 112 (27.3\%) males distributed in 3 different age groups. The mean $( \pm$ SD) ages of HIV positive and HIV negative subjects were $40.8( \pm 10.2)$ years and $27.9( \pm 15.7)$, respectively. The highest number of participants in the overall population was recorded in the $26-40$ years age group (191, 46.5\%). Only $8.3 \%$ (34) of the participants presented with fever. Amongst HIV positive patients, a total of $292(94.5 \%)$ were under ART while 17 (5.5\%) were not yet on ART, and $35.3 \%$ had CD4 T cell count $\geq 500$ cells $/ \mu \mathrm{L}$ of blood. The socio-economic, demographic and clinical data by HIV status of the study population is presented in Table 1 .

\section{Malaria parasite prevalence}

The overall prevalence of malaria in the study population was $14.1 \%$ (58). Malaria parasite prevalence was significantly higher $\left(x^{2}=41.36, P<0.001\right)$ in HIV negative $(33.3 \%, 34)$ than HIV positive participants $(7.8 \%, 24)$. The highest malaria parasite prevalence was recorded in the youngest age group in both HIV positive $(36.4 \%, 4)$ and HIV negative $(41.7 \%, 20)$ participants. As shown in Table 2, female participants among both HIV positive and HIV negative participants had a higher malaria parasite prevalence (8\%, 19 in HIV positive and $34.4 \%, 31$ in HIV negative) than their male counterparts (7\% in HIV positive and $31.7 \%$ in HIV negative); although only statistically significant in HIV positive patients $\left(\chi^{2}=11.98\right.$, $P=0.003$ ). Malaria parasite prevalence was significantly higher $\left(x^{2}=20.82, P=0.001\right)$ in HIV positive patients who presented with fever (37.5\%) than those who did not $(6.1 \%)$. The same trend of malaria parasite prevalence was observed amongst HIV negative participants, although the difference was not statistically significant $\left(x^{2}=1.29, P=0.20\right)$. Anaemic patients had a higher prevalence of malaria parasite $(11 \%$ in HIV positive and $39 \%$ in HIV negative) than non-anaemic patients $(3.7 \%$ in HIV positive and $29.5 \%$ in HIV negative). This difference was statistically significant only among HIV positive patients $\left(X^{2}=5.67, P=0.01\right)$ as shown in Table 2 . Out of the 214 anaemic patients, those with moderate
Table 1 Baseline characteristics of the study population

\begin{tabular}{|c|c|c|c|}
\hline Parameters & $\begin{array}{l}\text { HIV POSITIVE } \\
\text { n (\%) }\end{array}$ & $\begin{array}{l}\text { HIV NEGATIVE } \\
\text { n (\%) }\end{array}$ & $\begin{array}{l}\text { TOTAL } \\
\mathrm{n}(\%)\end{array}$ \\
\hline \multicolumn{4}{|l|}{ Age groups (years) } \\
\hline$\leq 25$ & $11(3.6)$ & $48(47.1)$ & $59(14.4)$ \\
\hline $26-40$ & $156(50.5)$ & $35(34.3)$ & $191(46.5)$ \\
\hline$>40$ & $142(46.0)$ & 19 (18.6) & $161(39.2)$ \\
\hline \multicolumn{4}{|l|}{ Sex } \\
\hline Female & $238(77.0)$ & $61(59.8)$ & $299(72.7)$ \\
\hline Male & $71(23.0)$ & $41(40.2)$ & $112(27.3)$ \\
\hline \multicolumn{4}{|l|}{ Educational Level } \\
\hline No formal & $30(9.7)$ & $3(3.4)$ & $33(8.3)$ \\
\hline Primary & $135(43.7)$ & $22(25.0)$ & $157(39.5)$ \\
\hline Secondary & $124(40.1)$ & $45(51.1)$ & $169(42.6)$ \\
\hline Tertiary & $20(6.5)$ & $18(20.5)$ & $38(9.6)$ \\
\hline ITN usage & $196(63.4)$ & $53(52.0)$ & $249(60.6)$ \\
\hline IRS usage & $78(25.2)$ & $26(25.5)$ & $104(25.3)$ \\
\hline \multicolumn{4}{|l|}{ Clinical } \\
\hline \multicolumn{4}{|c|}{ 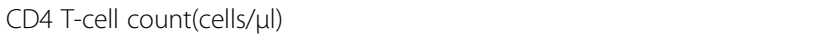 } \\
\hline$<200$ & $41(23.7)$ & & $41(23.7)$ \\
\hline $200-499$ & $71(41.0)$ & & $71(41.0)$ \\
\hline$>500$ & $61(35.3)$ & & $61(35.3)$ \\
\hline ART usage & $292(94.5)$ & & $292(94.5)$ \\
\hline \multicolumn{4}{|l|}{ ART Duration (months) } \\
\hline$<12$ & $33(10.8)$ & & $33(10.8)$ \\
\hline $12-35$ & $82(26.8)$ & & $82(26.8)$ \\
\hline$\geq 36$ & $191(61.8)$ & & $191(61.8)$ \\
\hline Fever prevalence & $16(5.2)$ & $18(17.6)$ & $34(8.3)$ \\
\hline Malaria prevalence & $24(7.8)$ & $34(33.3)$ & $58(14.1)$ \\
\hline Anaemia prevalence & $173(56.0)$ & $41(40.2)$ & $214(52.1)$ \\
\hline \multicolumn{4}{|l|}{ Anaemia severity } \\
\hline Mild & $95(54.9)$ & $16(39)$ & $111(51.9)$ \\
\hline Moderate & 69 (39.9) & $22(53.7)$ & $91(42.5)$ \\
\hline Severe & $9(5.2)$ & $3(7.3)$ & $12(5.6)$ \\
\hline
\end{tabular}

anaemia had the statistically significant $\left(x^{2}=7.44, P=\right.$ $0.024)$ highest prevalence of malaria parasite $(24.2 \%, 22)$. With respect to HIV status, analysis revealed that participants who had moderate anaemia (18.8\% in HIV positive and $40.9 \%$ in HIV negative) had the highest prevalence of malaria parasite as compare to their respective counterparts; though the difference was only significant for HIV positive patients $\left(\chi^{2}=7.53, P=0.02\right)$ (Table 2).

Among the $17 \mathrm{HIV}$ positive participants who had not started the ART, prevalence of malaria parasite was higher $(23.5 \%, 4)$ compared with the 292 patients under 
Table 2 Malaria parasite prevalence in HIV positive and negative participants

\begin{tabular}{|c|c|c|c|c|c|c|c|c|c|}
\hline \multirow[t]{2}{*}{ Categories } & \multicolumn{3}{|c|}{ HIV Positive } & \multicolumn{3}{|c|}{ HIV Negative } & \multicolumn{3}{|c|}{ Overall } \\
\hline & $\bar{n}$ & Malaria parasite positive $\%(n)$ & $x^{2}, P$ & $\bar{n}$ & Malaria parasite positive $\%(n)$ & $X^{2}, P$ & $\bar{N}$ & Malaria parasite positive $\%(n)$ & $X^{2}, P$ \\
\hline \multicolumn{10}{|l|}{ Gender } \\
\hline Female & 238 & $8.0(19)$ & 11.98 & 61 & $34.4(21)$ & 0.068 & 299 & $13.4(40)$ & 0.48 \\
\hline Male & 71 & $7.0(5)$ & $0.003^{*}$ & 41 & $31.7(13)$ & 0.51 & 112 & $16.1(18)$ & 0.29 \\
\hline \multicolumn{10}{|l|}{ Age (years) } \\
\hline$\leq 25$ & 11 & $36.4(4)$ & 13.06 & 48 & $41.7(20)$ & 3.14 & 59 & $40.7(24)$ & 40.34 \\
\hline $26-40$ & 156 & $6.4(10)$ & 0.001 & 35 & $28.6(10)$ & 0.21 & 191 & $10.5(20)$ & $<0.001^{*}$ \\
\hline$>40$ & 142 & $7.0(10)$ & & 19 & 21.1(4) & & 161 & $8.7(14)$ & \\
\hline \multicolumn{10}{|l|}{ Fever status } \\
\hline Febrile & 16 & $35(6)$ & 20.82 & 18 & $44.4(8)$ & 1.29 & 34 & $41.2(14)$ & 22.40 \\
\hline Afebrile & 293 & $6.1(18)$ & $0.001^{*}$ & 84 & $31.0(26)$ & 0.20 & 377 & $11.7(44)$ & $<0.001^{*}$ \\
\hline \multicolumn{10}{|l|}{ Anaemic status } \\
\hline Anaemic & 173 & $11.0(19)$ & 5.67 & 41 & $39.0(16)$ & 0.99 & 214 & $16.4(35)$ & 1.854 \\
\hline Non-anaemic & 136 & $3.7(5)$ & $0.01^{*}$ & 61 & $29.5(18)$ & 0.22 & 197 & $11.7(23)$ & 0.11 \\
\hline \multicolumn{10}{|l|}{ Anaemia severity } \\
\hline Mild & 95 & $5.3(5)$ & 7.537 & 16 & $37.5(6)$ & 0.089 & 111 & $9.9(11)$ & 7.443 \\
\hline Moderate & 69 & $18.8(13)$ & $0.02^{*}$ & 22 & $40.9(9)$ & 0.95 & 91 & $24.2(91)$ & $0.024^{*}$ \\
\hline Severe & 9 & $11.1(1)$ & & 3 & $33.3(1)$ & & 12 & $16.7(2)$ & \\
\hline \multicolumn{10}{|l|}{ Educational level } \\
\hline Primary & 135 & $6.7(9)$ & 5.78 & 22 & 40.9(9) & 3.94 & 157 & 11.5(18) & 5.68 \\
\hline Secondary & 124 & $5.6(7)$ & 0.05 & 45 & $22.2(10)$ & 0.27 & 169 & $10.1(17)$ & 0.20 \\
\hline Tertiary & 20 & $15.0(3)$ & & 18 & $33.3(6)$ & & 38 & 23.7(9) & \\
\hline None & 30 & $16.7(5)$ & & 3 & $0.0(0)$ & & 33 & $15.2(5)$ & \\
\hline \multicolumn{10}{|l|}{ ART use } \\
\hline Yes & 292 & $6.8(20)$ & 6.23 & & & & 292 & $6.8(20)$ & 6.23 \\
\hline No & 17 & $23.5(4)$ & $0.03^{*}$ & & & & 17 & $23.5(4)$ & $0.03^{*}$ \\
\hline \multicolumn{10}{|l|}{ Duration on ART } \\
\hline$<12$ months & 33 & $18.2(6)$ & 6.05 & & & & 33 & $18.2(6)$ & 6.05 \\
\hline 12-35 months & 82 & $6.1(5)$ & 0.06 & & & & 82 & $6.1(5)$ & 0.06 \\
\hline$\geq 36$ months & 191 & $6.3(12)$ & & & & & 191 & $6.3(12)$ & \\
\hline \multicolumn{10}{|l|}{ CD4T-cell (cells/ul) } \\
\hline$<200$ & 41 & $4.9(2)$ & 0.21 & & & & 41 & $4.9(2)$ & 0.21 \\
\hline $200-499$ & 71 & $7.0(5)$ & 0.90 & & & & 71 & $7.0(5)$ & 0.90 \\
\hline$\geq 500$ & 61 & $6.6(4)$ & & & & & 61 & $6.6(4)$ & \\
\hline
\end{tabular}

* Statistically significant $P$ value

ARV therapy $(6.8 \%, 20)$. This difference was statistically significant $\left(X^{2}=6.23, P=0.03\right)$. With respect to duration on ART, HIV positive participants who have been on therapy for $\leq 12$ months had the highest prevalence of malaria parasite $(18.2 \%, 6)$ compared with those who had been taking their medications for a longer period. However, the difference was not statistically significant $\left(X^{2}=6.05, P=0.06\right)$.

\section{Malaria preventive measures}

In the overall population, participants not using insecticide treated nets (ITNs) had a higher prevalence of malaria parasites $(16 \%, 26)$ than those who used ITNs $(12.9 \%$, $32)$, but the difference was not significant $\left(\chi^{2}=0.57, P=\right.$ 0.27). Participants using IRS as their preventive measure had a non-statistically higher prevalence of malaria parasites $(16.3 \%, 17)$ than those not using it $(13.4 \%, 41)$. 
Among HIV positive participants, those who did not use ITN nor IRS had a higher malaria parasite prevalence $(10.6 \%$ [12/113]), 8.2\% [19/231]) than those who used ITN or IRS $(6.1 \%$ [12/196], 6.4\% [5/78]), respectively. However, the differences were not significant $(P=$ $0.41, P=0.12$ ). Among HIV negative participants, those who did not use ITN nor IRS had a lower malaria parasite prevalence $(28.6 \%, 14 ; 28.9 \%, 22$ respectively) as compared to their respective counterparts $(37.7 \%, 20$; $46.2 \%, 12)$. These differences were not statistically significant $(P=0.8, P=0.15)$.

As shown in Fig. 1, when the two preventive methods were compared, the lowest malaria parasite prevalence was recorded among participants who used both preventive measures. When comparing the usage of both preventive measures among HIV positive and HIV negative participants, it was observed that those who did not implement any preventive measure had the highest malaria parasite prevalence in HIV positive patients $(10.1 \%$, 8/79) which was the opposite among HIV negative participants; those not implementing preventive measures had the lowest malaria parasite prevalence $(22.6 \%, 7 / 31)$ (Fig. 1).

\section{Anaemia prevalence and Anaemia severity}

The overall prevalence of anaemia in the study population was $52.1 \%(214)$. Anaemia prevalence was significantly higher $\left(X^{2}=7.00, P=0.004\right)$ in HIV positive patients $(56 \%, 173)$ than their HIV negative counterparts $(40.2 \%, 41)$. HIV positive patients and HIV negative participants in the age groups $26-40$ years $(59.0 \%)$ and $\leq 25$ years $(52.1 \%)$, respectively had the highest prevalence of anaemia as compared to their age-group counterparts, though the differences were not statistically significant. Anaemia prevalence was higher in female participants (64.7\%, 154 in HIV positive and 49.2\%, 30 in HIV negative) compared to male participants $(26.8 \%, 19$ in HIV positive and $26.8 \%, 11$ in HIV negative). These differences were statistically significant for both HIV positive patients $(P=0.001)$ and their HIV negative counterparts $(P=0.02)$. With respect to malaria status, both in HIV positive and HIV negative participants, anaemia prevalence was higher in those who were positive for malaria parasite than those who were not. Within both categories of patients, febrile patients had a higher prevalence of anaemia (56.2\%, 9 in HIV positive and 55.6\%, 10 in HIV negative) than their afebrile counterparts $(56 \%, 164$ in HIV positive and $36.9 \%, 31$ in HIV negative). HIV positive patients with CD4 T-cell count $<200$ cells had the highest prevalence of anaemia $(73.2 \%)$ that approached significance $(P=0.05)$ when compared to their counterparts. As shown in Table 3, although not significant $(P=$ 0.31 ), HIV patients not on ART had a higher prevalence of anaemia $(64.7 \%, 11)$ than those on ART $(55.5 \%, 162)$.

With respect to anaemia severity, $51.9 \%$ (111) of the anaemic patients had mild anaemia, $42.5 \%$ (91) had moderate anaemia and 5.9\% (12) had severe anaemia in the overall study population.

As shown in Fig. 2, HIV positive patients had lower mean haemoglobin level when compared to HIV negative participants; though the difference in mean was not statistically significant $(P=0.40)$.

\section{Effect of malaria/HIV co-infection on Haematological parameters}

Malaria/HIV co-infection was observed in 24 patients (5.8\%) while those who had only malaria were $34(8.3 \%)$. The mean values of 14 haematological parameters were compared between malaria/HIV co-infected patients and only HIV-infected patients. Seven haematological parameters $(\mathrm{Hb}, \mathrm{RBC}, \mathrm{MCV}, \mathrm{MCH}$, Lymphocyte count, Hct, PDW) showed lower mean value among malaria/HIV coinfected patients when compared with HIV-infected patients. The difference was statistically significant for $\mathrm{Hb}$

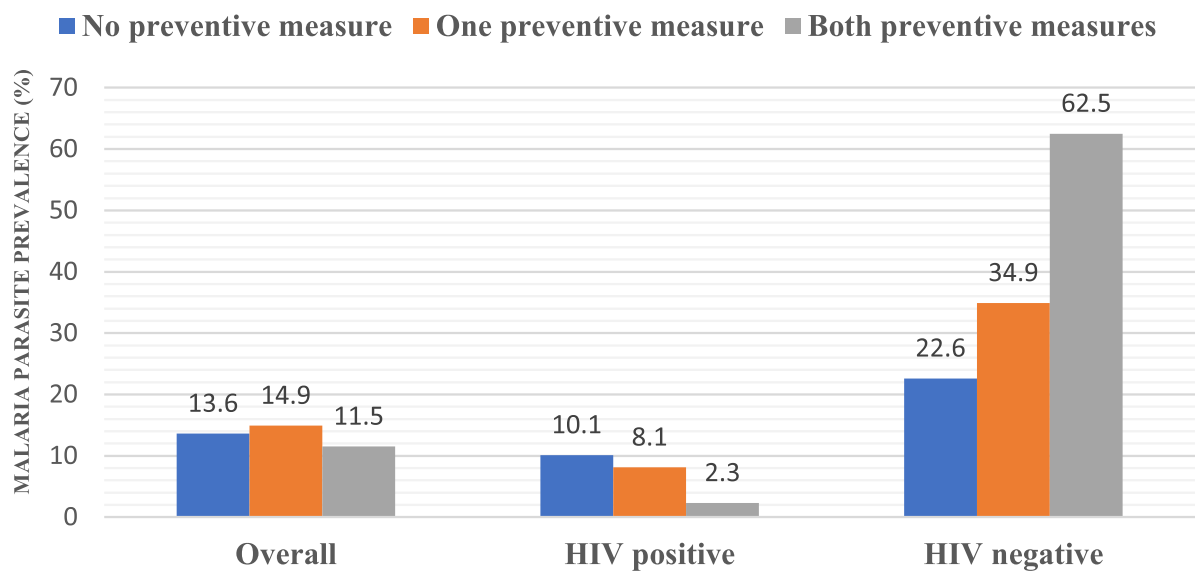

Fig. 1 Malaria parasite prevalence with respect to implementation of malaria preventive measures 
Table 3 Prevalence of anaemia as affected by sociodemographic and clinical factors in HIV positive and HIV negative participants

\begin{tabular}{|c|c|c|c|c|c|c|c|c|c|}
\hline \multirow[t]{2}{*}{ Categories } & \multicolumn{3}{|c|}{ HIV Positive } & \multicolumn{3}{|c|}{ HIV Negative } & \multicolumn{3}{|c|}{ Overall } \\
\hline & $\bar{n}$ & Anaemia prevalence $(\mathrm{n})$ & $\begin{array}{l}X^{2} \\
P\end{array}$ & $\mathrm{n}$ & Anaemia prevalence $(n)$ & $\begin{array}{l}x^{2} \\
P\end{array}$ & $\bar{N}$ & Anaemia prevalence $(n)$ & $\begin{array}{l}X^{2} \\
P\end{array}$ \\
\hline \multicolumn{10}{|l|}{ Gender } \\
\hline Female & 238 & $64.7(154)$ & 31.9 & 61 & $49.2(30)$ & 5.16 & 299 & $61.5(184)$ & 39.4 \\
\hline Male & 71 & $26.8(19)$ & $0.001^{*}$ & 41 & $26.8(11)$ & $0.02^{*}$ & 112 & $26.8(3+0)$ & $<0.001^{*}$ \\
\hline \multicolumn{10}{|l|}{ Age group (years) } \\
\hline$\leq 25$ & 11 & $54.5(6)$ & 1.15 & 48 & $52.1(25)$ & 5.37 & 59 & $52.5(31)$ & 0.34 \\
\hline $26-40$ & 156 & $59.0(92)$ & 0.56 & 35 & 28.6(10) & 0.07 & 191 & $53.4(102)$ & 0.84 \\
\hline$>40$ & 142 & $52.8(75)$ & & 19 & $31.6(6)$ & & 161 & $50.3(81)$ & \\
\hline \multicolumn{10}{|l|}{ Malaria status } \\
\hline Malaria positive & 24 & 79.2(19) & 5.67 & 34 & $47.1(16)$ & 0.99 & 58 & $60.3(35)$ & 1.85 \\
\hline Malaria negative & 285 & $54.0(154)$ & 0.01 & 68 & $36.9(25)$ & 0.22 & 353 & $50.7(79)$ & 0.11 \\
\hline \multicolumn{10}{|l|}{ Fever status } \\
\hline Febrile & 16 & $56.2(9)$ & 0.001 & 18 & $55.6(10)$ & $x^{2}=2.14$ & 34 & $55.9(19)$ & 0.21 \\
\hline Afebrile & 293 & $56.0(164)$ & 0.50 & 84 & $36.9(31)$ & $P=0.11$ & 377 & $51.7(195)$ & 0.38 \\
\hline \multicolumn{10}{|l|}{ ARV use } \\
\hline Yes & 292 & $55.5(162)$ & 0.55 & & & & 292 & $55.5(162)$ & 0.55 \\
\hline No & 17 & $64.7(11)$ & 0.31 & & & & 17 & $64.7(11)$ & 0.31 \\
\hline \multicolumn{10}{|l|}{ Duration on ARV } \\
\hline$<12$ months & 33 & $63.6(21)$ & 0.86 & & & & 33 & $63.6(21)$ & 0.86 \\
\hline $12-35$ months & 82 & $56.1(46)$ & 0.42 & & & & 82 & $56.1(46)$ & 0.42 \\
\hline$\geq 36$ months & 191 & $55.0(105)$ & & & & & 191 & $55.0(105)$ & \\
\hline \multicolumn{10}{|l|}{ 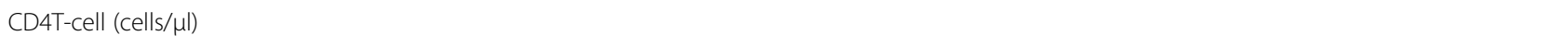 } \\
\hline$<200$ & 41 & $73.2(30)$ & 3.78 & & & & 41 & $73.2(30)$ & 3.78 \\
\hline $200-499$ & 71 & $60.6(43)$ & 0.05 & & & & 71 & $60.6(43)$ & 0.05 \\
\hline$\geq 500$ & 61 & $54.1(33)$ & & & & & 61 & $54.1(33)$ & \\
\hline
\end{tabular}

* statistically significant $P$ value

\section{$P=0.40$}

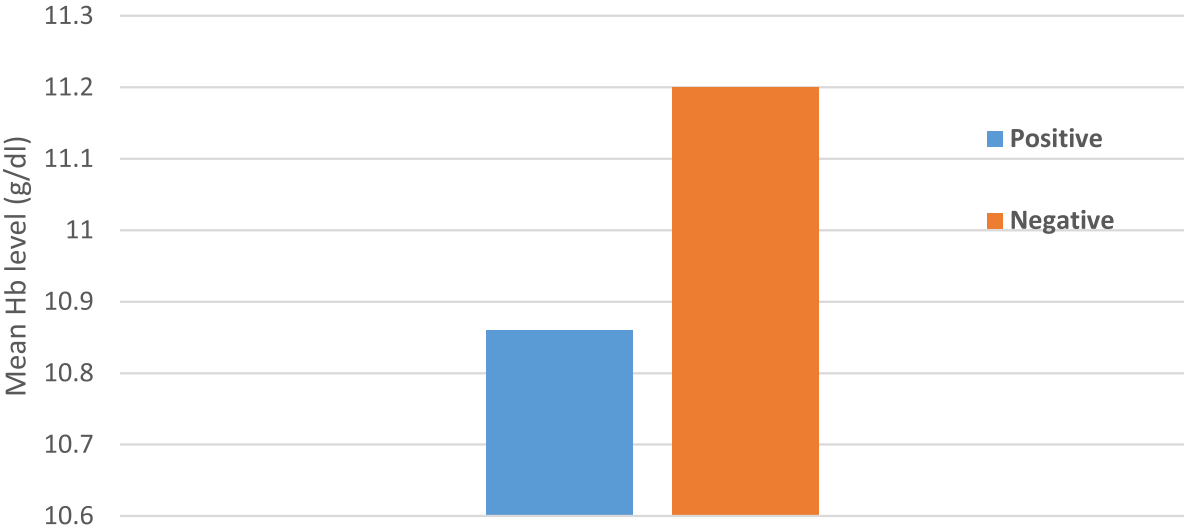

HIV STATUS

Fig. 2 Mean Haemoglobin level $(\mathrm{g} / \mathrm{dl})$ with respect to HIV status 
$(P=0.002)$, RBC $(P=0.002)$ and Hct $(P=0.001)$. Conversely, co-infected patients were observed to have higher mean values for WBC, PLT, MCHC, Granulocyte count, MPV, RDW-SD and RDW-CV than HIV-infected patients without malaria. The difference was not statistically significant as shown in Table 4.

\section{Discussion}

This study was a hospital-based cross-sectional study carried out to determine the prevalence of malaria parasites in HIV positive and HIV negative individuals at the Limbe Regional Hospital. Irrespective of the participants' HIV status, the overall malaria parasites prevalence was $14.1 \%$. This result is lower than the reported national malaria prevalence of $29 \%$ [22] and also lower than the $29.4 \%$ recorded in Douala [23] and 55.0\% recorded in Limbe [10]. This decrease could be as a result of the sustained malaria control strategies put in place by the Cameroon government over the past years both in HIV positive and HIV negative population. These strategies include the sensitization campaigns on how to better use LLINs, free distribution of ART to patients together with cotrimoxazole, increased number of care and treatment centers for HIV/AIDS patients and the use of Artemisinincombination therapy (ACT) as recommended by World Health Organization.

Interestingly, the prevalence of malaria parasites was higher in HIV negative participants (33.3\%) than their HIV positive counterparts (7.8\%). This is in line with a study carried out in Ethiopia [24] which also reported a higher malaria parasites prevalence in HIV negative participants than in their HIV positive counterparts. HIV positive patients attending HIV specialty unit are more likely to receive routine medical care follow-up and health maintenance compared to patients at the Outpatient department The fact that HIV negative participants were recruited from the Outpatient department of the hospital could also contribute to this high malaria parasites prevalence among them; as majority came to the hospital to seek for medical care due to the presence of acute symptoms of different illness including malaria. This finding also correlates with that of Njunda et al. [11] in Bamenda which reported a low prevalence of malaria parasites in HIV positive patients.

In accordance with Kasirye et al. [25], Amuta et al. [26] and Gennano et al. [27] malaria parasites prevalence was higher in HIV positive patients who were not on ART than those on ART. This may be likely due to the reconstitution of their immune system associated with the administration of the drugs, indicating that the ART is effective. The low prevalence in patients on ART could be as a result of the presence of cotrimoxazole as part of their therapy which has been shown to have some antimalarial properties that reduce the incidence of malaria in HIV patients. WHO recommends to stop cotrimoxazole in clinically stable patients with evidence of viral suppression under ART, while it should be continued in patients living in areas with high malaria and bacterial infection prevalence [28]. That is the case with Cameroon where cotrimoxazole is continuously given to all HIV patients irrespective of their viral suppression levels.

Table 4 Comparison of haematological parameters between HIV positive $(n=285)$ and HIV/malaria co-infected patients $(n=24)$ among the study population

\begin{tabular}{|c|c|c|c|c|}
\hline Haematological Parameters & Malaria/HIV co-infected (24) & HIV-infected (285) & T-test & $P$-values* \\
\hline$\overline{\mathrm{Hb} \mathrm{g} / \mathrm{dl}}$ & $9.75 \pm 1.67$ & $10.95 \pm 1.87$ & 3.331 & $0.002^{*}$ \\
\hline $\mathrm{RBC} \times 10^{12} / \mathrm{I}$ & $3.32 \pm 0.53$ & $3.73 \pm 0.66$ & 3.442 & $0.002^{*}$ \\
\hline WBC $\times 10^{9} / 1$ & $6.12 \pm 3.88$ & $5.88 \pm 2.51$ & -0.301 & 0.761 \\
\hline $\mathrm{PLT} \times 10^{9} / /$ & $170.96 \pm 79.01$ & $168.58 \pm 65.03$ & -0.147 & 0.890 \\
\hline $\mathrm{MCV} f \mathrm{l}$ & $94.63 \pm 9.97$ & $94.99 \pm 10.37$ & 0.173 & 0.862 \\
\hline $\mathrm{MCHC} \mathrm{g} / \mathrm{dl}$ & $31.34 \pm 1.04$ & $31.19 \pm 3.26$ & -0.526 & 0.601 \\
\hline $\mathrm{MCH} P g$ & $29.60 \pm 3.26$ & $29.61 \pm 4.63$ & 0.015 & 0.984 \\
\hline Lymphocyte Diff \% & $26.82 \pm 15.38$ & $29.81 \pm 11.38$ & 0.933 & 0.362 \\
\hline Granulocyte Diff \% & $62.33 \pm 14.47$ & $58.35 \pm 11.86$ & -1.311 & 0.20 \\
\hline Hct \% & $30.8 \pm 5.43$ & $35.26 \pm 6.06$ & 3.814 & $0.001^{*}$ \\
\hline RDW_CV fl & $13.54 \pm 2.51$ & $13.38 \pm 5.13$ & -0.265 & 0.797 \\
\hline RDW_SD \% & $51.54 \pm 8.15$ & $50.15 \pm 5.68$ & -0.823 & 0.422 \\
\hline MPV fl & $11.55 \pm 1.67$ & $11.43 \pm 1.76$ & -0.326 & 0.753 \\
\hline PDW & $8.46 \pm 1.62$ & $8.99 \pm 4.55$ & 1.247 & 0.221 \\
\hline
\end{tabular}

Values are mean \pm SD

*Statistically significant $P$ value

$P$ values were calculated using independent student $\mathrm{t}$-test 
Findings from the study also revealed that in both HIV positive and HIV negative patients, those who presented with fever had significantly higher malaria parasite prevalence than those who did not have fever. This confirms that the fever observed was likely because of the malaria parasite infection in the patient and this is in line with a study carried out in Gabon by BouyouAkotet et al. [29].

In this study, participants aged $\leq 25$ years of age were more infected with malaria parasites than participants of other age groups in both study groups. This result could have been due to the fact that the age group $\leq 25$ years includes children who are a vulnerable group when it comes to malaria as their immune system is still developing and also the young adults who stay out late thereby increasing chances to be bitten by an infected mosquito. This finding is in line with results reported form other studies carried out in the Southwest region of Cameroon by Apinjoh et al. [30]; Ebai et al. [31]; Amuta et al. 2012 [26] and I et al. [32].

Females had a higher prevalence of malaria parasites as compared to the males in this study. The fact that more females were recruited for this study more than males could have accounted for the difference as majority of males avoid coming for check-up in the hospital as a result of stigmatization [33]. This result is in line with a study carried out by Kimbi et al., [34] and contrary to what has been reported in other studies $[35,36]$ where males had a higher prevalence of malaria parasite due to the fact that they often engage themselves in late night activities and also often expose their chest, especially when the weather is hot and during farm work.

From this study, it was observed that anaemic patients had a higher prevalence of malaria parasites when compared with those who were not anaemic in both study populations. Malaria parasites cause destruction of red blood cells hence reducing haemoglobin levels leading to anaemia. This relationship has been well established in several studies in Cameroon and Africa [21, 37, 38].

Findings from the study revealed that a suitable number of participants used ITNs in their homes. The prevalence of malaria parasites was lower in those who used ITNs when compared with those who did not. This is because ITNs serves as a barrier to mosquitoes and so preventing transmission of the malaria parasites. This result is in line with findings in Kenya [39] which reported that sleeping under an ITN considerably reduces the risk of man-vector contact and consequently malaria infection. Among HIV positive patients, those who implemented two different preventive measures against malaria had the lowest malaria parasite prevalence. This is an indication that combination different preventive measures against malaria helps to better combat this infection. This finding give credit to the efficiency of possible integrated vector control measures against malaria. This aspect needs to be encouraged among both HIV positive and HIV negative individuals and emphasis made to HIV positive patients during their daily lectures at the HIV Centre.

In this study, the prevalence of anaemia was significantly higher in HIV positive patients than HIV negative participants. Several drugs used to combat HIV and its complications must have contributed to this high anaemia prevalence. Zidovudine has been reported to cause anaemia because of myelo-suppression [40]. Anaemia is also caused by different etiological agents including HIV-associated malignancies [41]. This result is in line with that reported by Ayukenchengamba et al. [42] and Ojurongbe et al. [43] in other studies.

In both HIV positive and HIV negative populations, females had a significantly higher prevalence of anaemia than males. This difference could be attributed to the menstrual blood loss in women and to the drains on iron stores that occur with pregnancy and delivery [41].

From our study, it was observed that mean value of $\mathrm{Hb}, \mathrm{RBC}$ and HCT were significantly lower in malaria/ HIV co-infected patients as compared with HIV-infected patients. This finding is consistent with previous studies done in Nigeria [44, 45] and Southeast Ethiopia [46]. This can be attributed to the combined effects of RBC destruction caused by the malaria parasites and the administration of Zidovudine which has been reported to cause anaemia.

This study also found that the mean lymphocyte count, granulocyte count and WBC were similar between HIV-infected patients and malaria/HIV co-infected patients $(P>0.05)$. This observation agrees with previous findings by Erhador et al. [44] and Tchinda et al. [15].

\section{Conclusion}

In general, malaria parasite prevalence was higher in HIV negative than in HIV positive participants attending the Regional Hospital Limbe. The prevalence of anaemia was high in the overall population and was the main haematological abnormality observed amongst HIV positive patients. Three blood parameters $(\mathrm{Hb}, \mathrm{RBC}, \mathrm{Hct})$ were significantly different between malaria/HIV coinfected patients and HIV-infected patients. These findings also revealed that malaria may not be the primary cause of haematological abnormalities in these patients. To confirm these results, a community-based crosssectional study needs to be carried out to have a clear picture of the malaria parasite prevalence of HIV negative subjects in the community; which could be later on compared with their HIV positive counterparts. The study had as limitation the fact that both categories of participants visited the hospital for different reasons; one to seek for medical attention at the OPD while the other 
for normal routine follow-up. So these different reasons to some extend could have contributed to the difference in malaria prevalence and other clinical parameters. Therefore, prospective studies with large sample size from other settings are needed to substantiate these findings.

\section{Supplementary information}

Supplementary information accompanies this paper at https://doi.org/10. 1186/s12879-019-4629-4.

Additional file 1. Questionnaire, Socio-demographic and clinical data of the participants.

\begin{abstract}
Abbreviations
ACT: Artemisinin Combination Therapy; AIDS: Acquired Immune Deficiency Syndrome; ANOVA: Analysis of Variance; ART: Anti-retroviral Therapy; ARV: Anti-retroviral (drug); CD4 T: T-lymphocyte cell bearing CD4 receptors; CDC: Center for Disease Control and Prevention; CNLS: Comité National de Lutte contre le SIDA; GTC: Groupe Technique Central National; Hb: Haemoglobin; HIV: Human Immunodeficiency Virus; IRS: Insecticide Residual Spraying; ITNs: Insecticide-Treated Nets; MCH: Mean Corpuscular Haemoglobin; MCHC: Mean Corpuscular Haemoglobin Concentration; MCV: Mean Corpuscular Volume; MPV: Mean Platelet Volume; OIHC: Office for Institutional HIV Co-ordination; OPD: Out Patient Department; P: Probability Level; PLT: Platelets; RBCs: Red Blood Cells; RDW: Red Cell Distribution Width; RHL: Regional Hospital Limbe; SPSS: Software Package of Social Sciences; UNAIDS: Joint United Nations Programme on HIV/AIDS; WBC: White Blood Cell; WHO: World Health Organization
\end{abstract}

\section{Acknowledgments}

The authors are so grateful to the participants (both children and adults) who took part in the study as well as to the staff of the Voluntary, Counseling, Testing and Treatment Center (VCTTC) and the laboratory of the Regional Hospital Limbe for letting the practical aspect of this study go on smoothly with no incidents, for their guidance and critical comments concerning the care given to their patients.

\section{Authors' contributions}

SMS conceived the study, designed and coordinated the field work, data collection and analysis as well as the write-up of the manuscript. IUNS conceived and designed the study, participated in data analysis and revision of the manuscript. MMT was involved in data collection, interview of the participants and data analysis. HKK conceived and designed the study, data collection and analysis and revised the manuscript critically for important intellectual content. All authors read and approved the manuscript.

\section{Funding}

This work was supported by the special fund for research and modernization given to authors by the Government of Cameroon. With the availability of the funds, the authors conveniently designed the work. The funds supported transportation to the field for sample collection, purchase of supplies and equipment for sample analyses. Interpretation of the data and writing of the manuscript were done by the authors.

\section{Availability of data and materials}

All datasets on which the conclusions of the research rely are presented in this paper. However, data is available from the corresponding author on reasonable request.

\section{Ethics approval and consent to participants}

Prior to the start of the study, an administrative clearance was obtained from the South West Regional Delegation of Public Health, Buea, followed by an ethical clearance from the Institutional Review Board hosted by the Faculty of Health Sciences of the University of Buea (2014-07-0293/UB/FHS/IRB). Inform consent and assent forms were given and explained to the adult participants and parents/guardians of children ( $\leq 16$ years) at presentation. All participants were informed about the objective and benefits of the study.
The amount of blood to be collected from each participant was clearly stated on the consent/assent forms. Only participants who gave written consent or assent for children took part in the study. Pre- and post-HIV counselling was done by competent personnel. All test procedures were done free of charge with confidentiality maintained. Participants could ask questions and their decisions not to participate in the study were fully respected and this did not affect the services provided to them in any way. They were also free to withdraw from the study at any time that they wished. All information collected from the field remained strictly confidential.

\section{Consent for publication}

Not applicable.

\section{Competing interests}

The authors declare that they have no competing interests.

\section{Author details}

${ }^{1}$ Department of Zoology and Animal Physiology, University of Buea, Buea, Cameroon. ${ }^{2}$ Department of Medical Laboratory Science, University of Bamenda, Bambili, Cameroon.

Received: 18 February 2019 Accepted: 11 November 2019

Published online: 21 November 2019

\section{References}

1. World Health Organization. World Malaria Report 2018. http://www.who. int/malaria/publications/world-malaria-report-2018/en/ 2018. Accessed 18 Sept 2019

2. Mangham LJ, Cundill B, Achonduh OA, Ambebila JN, Lele AK, Metoh TN, Ndive SN, Ndong IC, Nguela RL, Nji AM, Orang-Ojong B, Pamen-Ngako J, Wiseman V, Mbacham WF. Malaria prevalence and treatment of febrile patients at health facilities and medicine retailers in Cameroon. Tropical Med Int Health. 2012;17(3):330-42.

3. Ossono EN, Fosso MY, Missoko P. HIV AIDS in Cameroon-An update, 2013. The Denis and Lenora Foretia Foundation. https://www.foretiafoundation. org/hiv-aids-in-cameroon-an-update/ 2013. Accessed 16 Feb 2019.

4. Nathoo S, Serghiedes L, Kain K. Effect of HIV-1 antiretroviral drugs on cytoadherence and phagocytic clearance of Plasmodium falciparum parasitized erythrocytes. Lancet. 2003;362(9389):1039-41.

5. Skinner-Adams T, McCarthy J, Gardiner D, Hilton P, Andrews K. Antiretroviral as anti-Malarian agents. J Infect Dis. 2004;190(11):1998-2000.

6. Manyanga VP, Minzi O, Ngasala B. Prevalence of malaria and anaemia among HIV infected pregnant women receiving cotrimoxazole prophylaxis in Tanzania: a cross sectional study in Kinondoni municipality. BMC Pharmacol Toxicol. 2014;15:24. https://doi.org/10.1186/2025-6511-15-24.

7. Rosenthal PJ. Cysteine proteases of malaria parasites. Int J Parasitol. 2004;34: 1489-99.

8. Joint United Nations Programme on HIV/AIDS (UNAIDS). UNAIDS report on the global AIDS epidemic 2018, Geneva, Switzerland. http://www.unaids.org/en/ media/unaids/contentassets/documents/epidemiology/2012/gr2/ 2018.

9. Joint United Nations Programme on HIV/AIDS (UNAIDS). UNAIDS report on the global AIDS epidemic 2014, Geneva, Switzerland. http://www.unaids.org/en/ media/unaids/contentassets/documents/epidemiology/2014/gr2/ 2014.

10. Kimbi HK, Njoh DT, Ndamukong KJN, Lehman LG. Malaria in HIV/AIDS patients at different CD4 T cell levels in Limbe, Cameroon. J Bacteriol Parasitol. 2013;4:164. https://doi.org/10.4172/2155-9597.1000164.

11. Njunda LA, Kamga HLF, Nsagha DS, Assoh JCN, Kwenti TE. Low malaria prevalence in HIV-positive patients in Bamenda, Cameroon. J Microbiol Res. 2012;2:56-9.

12. Nkuo-Akenji T, Tevoufouet EE, Nzang F, Fon E, Ebong IN. HIV/AIDS and malaria in pregnant women from Cameroon short running title: HIV, malaria in pregnancy. Afr J Health Sci. 2011;18:105-9.

13. Tamez P, Liu H, Fernandez-Pol S. Stage-specific susceptibility of human erythroblasts to Plasmodium falciparum malaria infection. Blood. 2009;114: 3652-5.

14. Erhart L, Yingyuen K, Chuanak N, Buathong N, Laoboonchai A, Miller R, Meshnick S, Gasser R Jr, Wongsrichanalai C. Haematological and clinical indices of malaria in a semi-immune population of western Thailand. Am J Trop Med Hyg. 2004;70:8-14.

15. Tchinda G, Atashili J, Achidi E, Kamga H, Njunda LA, Ndumbe P. Impact of malaria on haematological parameters in people living with HIV/AIDS 
attending the Laquintinine Hospital in Douala, Cameroon. PLoS ONE. 2012; 7(7):e40553.

16. Modiano J, Sirima B, Konate A, Sanou I, Sawadogo A. Leucocytosis in severe malaria. Trans R Soc Trop Med Hyg. 2001;95:175-6.

17. Dikshit B, Wanchu A, Sachdeva RK, Sharma A, Das R. Profile of haematological abnormalities of Indian HIV infected individuals. BMC Blood Disord. 2009;9:5.

18. United Councils and Cities of Cameroon (UCCC), National Bureau. http://www.cvuc.cm/national/index.php/en 2014. Accessed 18 Feb 2019.

19. Bryan FJ. The design and analysis of research studies, University of Otago, Dunedin, New Zealand. Cambridge: Cambridge University Press; 1992.

20. Cheesbrough M. District laboratory practice in tropical countries part1 and 2. Cambridge low price editions. 2nd ed. Cambridge: Cambridge University Press; 2009

21. Sumbele IUN, Sama SO, Kimbi HK, Taiwe GS. Malaria, moderate to severe anaemia, and malarial anaemia in children at presentation to hospital in the Mount Cameroon Area: A cross-sectional study. Anemia 2016; Article ID 5725634:12 pg.

22. World Health Organization. World Malaria Report 2018. Cameroon, African Region https://www.who.int/malaria/publications/country-profiles/profile_ cmr_en.pdf?ua=1 2018. Accessed 18 Sept 2019.

23. Nkuo-Akenji T, Tevoufouet EE, Mzang F, Ngufor N, Fon E. Higher prevalence of HIV and malaria co-infection in urban Douala, Cameroon. Afr J AIDS Res. 2008;7(2):229-32.

24. Alemayehu G, Melaku Z, Abreha T, Alemayehu B, Girma S, Tadesse Y, Gadisa T, Lulseged S, Balcha TT, Hoos D, Teka H, Reithinge R. Burden of malaria among adult patients attending general medical outpatient department and HIV care and treatment clinics in Oromia, Ethiopia: a comparative crosssectional study. Malar J. 2015;14:501.

25. Kasirye R, Levin J, Munderi P, Okell L, Walker S,Mugisha A. Epidemiology of malaria in HIV infected Ugandan patients on antiretroviral therapy (ART) - a prospective cohort study. $5^{\text {th }}$ IAS conference on HIV pathogenesis, treatment and prevention. 2009.

26. Amuta EU, Houmsou RS, Diya AW. Malarial infection among HIV patients on antiretroviral therapy (ART) and not on ART: a case study of Federal Medical Centre Makurdi, Benue state, Nigeria. Asian Pac J Trop Biomed. 2012;2:S378-81.

27. Gennaro FD, Marotta C, Pizzol D, Chhaganlal K, Monno L, Putoto G, Saracino A, Casuccio A, Mazzucco W. Prevalence and predictors of malaria in human immunodeficiency virus infected patients in Beira, Mozambique. Int J Environ Res Public Health. 2018;15:2032.

28. World Health Organization (WHO). Guidelines on Postexposure Prophylaxis for HIV and the Use of Co-Trimoxazole Prophylaxis for HIV-Related Infections among Adults, Adolescents and Children: Recommendations for a Public Health Approach. Geneva: WHO; 2014

29. Bouyou-Akotet M, Offouga C, Mawili-Mboumba D, Essola L, Madoungou B, Kombila M. Falciparum malaria as an emerging cause of fever in adults living in Gabon, Central Africa. Biomed Res Int. 2014:Article ID 351281. https://doi.org/10.1155/2014/351281.

30. Apinjoh TO, Anchang-Kimbi JK, Mugri RN, Tangoh DA, Nyingchu RV, Chi HF. The effect of insecticide treated nets (ITNs) on Plasmodium falciparum infection in rural and semi urban communities in the south west region of Cameroon. PLoS One. 2015;10:e0116300. https://doi.org/10.1371/journal. pone.0116300.

31. Ebai CB, Kimbi HK, Sumbele IUN, Yunga JE, Lehman LG. Epidemiology of Plasmodium falciparum malaria in the Ikata-Likoko area of Mount Cameroon: a cross sectional study. Int J Trop Dis Health. 2016;16:1-12. https://doi.org/10.9734/IJTDH/2016/25890.

32. I RN, Sumbele IUN, Meduke DN, Ojong ST, Kimbi HK. Malaria parasitaemia, anaemia and malnutrition in children less than 15 years residing in different altitudes along the slope of Mount Cameroon: prevalence, intensity and risk factors. Malar J. 2018;17:336. https://doi.org/10.1186/s12936-018-2492-1.

33. Uneke CJ, Ogbu O, Inyama PU, Anyanwu GI. Malaria infection in HIVseropositive and HIV-seronegative individuals in Jos-Nigeria. J Vector Borne Dis. 2005;42:151-4.

34. Kimbi HK, Sumbele IUN, Nweboh M, Anchang-Kimbi JK, Lum E, Nana Y, Ndip LM, Njom H, Lehman LG. Malaria and haematologic parameters of pupils at different altitudes along the slope of Mount Cameroon: a crosssectional study. Malar J. 2013;12:193.

35. Kimbi HK, Nana Y, Sumbele IN, Anchang-Kimbi JK, Lum E, et al. Environmental factors and preventive methods against malaria parasite prevalence in rural Bomaka and urban Molyko, Southwest Cameroon. J Bacteriol Parasitol. 2013:4:162. https://doi.org/10.4172/2155-9597.1000162.

36. Baume CA, Reithinger R, Woldehanna S. Factors associated with use and non-use of mosquito nets owned in Oromia and Amhara regional states, Ethiopia. Malar J. 2009;8:264.

37. Kahigwa E, Schellenberg D, Sanz S, Aponte JJ, Wigayi J, Mshinda H, Alonso $P$, Menendez C. Risk factors for presentation to hospital with severe anaemia in Tanzanian children: a case-control study. Tropical Med Int Health. 2002;7:823-30.

38. Achidi EA, Kuoh AJ, Minang JT, Ngum B, Achimbom BM, Motaze SC, Ahmadou MJ, Troye-Blomberg M. Malaria infection in pregnancy and its effects on haemoglobin levels in women from a malaria endemic area of Fako Division, South west Province, Cameroon. J Obstet Gynaecol. 2009; 25(3):235-40.

39. Atieli H, Zhou G, Afrane Y, Lee M-C, Mwanzo I, Githeko A, Yan G. Insecticidetreated net (ITN) ownership, usage and malaria transmission in the highlands of western Kenya. Parasit Vectors. 2011:4:113.

40. Blake M, Sherer R. Management of the adverse effects of antiretroviral therapy and medication adherence. Clin Infect Dis. 2000;30(Suppl 2):S96116. https://doi.org/10.1086/313859.

41. Breymann C. Iron deficiency anemia in pregnancy. Semin Hematol. 2015; 52(4):339-47.

42. Bate A, Kimbi HK, Lum E, Lehman LG, Onyoh EF, Ndip LM, Njabi CM, Tonga C, Wempnje GB, Ndip RN, Bessong PO. Malaria infection and anaemia in HIV-infected children in Mutengene, Southwest Cameroon: a cross sectional study. BMC Infect Dis. 2016;16:523.

43. Ojurongbe O, Oyeniran O, Alli O, Taiwo S, Ojurongbe T, Olowe A, Opaleye $\mathrm{O}$, Adeyeba O. Prevalence of Plasmodium falciparum Parasitaemia and its correlation with haematological parameters among HIV-Positive individuals in Nigeria. J Trop Med Hyg. 2014:Article ID 161284. https://doi.org/10.1155/ 2014/161284

44. Erhabor O, Babatunde S, Uko KE. Some haematological parameters in Plasmodial parasitized HIV-infected Nigerians. Niger J Med. 2006;15(1):52-5.

45. Etusim PE, Ihemanma CA, Nduka FO, P.E. M, Ukpai O. Comparative study on the haematological characteristics of malaria infected and malaria noninfected persons referred to art/HIV laboratory, Abia State University teaching hospital, aba, Abia state. J Sci Multidiscip Res. 2013;5(1):100-12.

46. Sahle T, Yemane T, Gedefaw L. Effect of malaria infection on haematological profiles of people living with human immunodeficiency virus in Gambella, Southwest Ethiopia. BMC Hematol. 2017;17:2. https://doi.org/10.1186/ s12878-017-0072-1.

\section{Publisher's Note}

Springer Nature remains neutral with regard to jurisdictional claims in published maps and institutional affiliations.

Ready to submit your research? Choose BMC and benefit from

- fast, convenient online submission

- thorough peer review by experienced researchers in your field

- rapid publication on acceptance

- support for research data, including large and complex data types

- gold Open Access which fosters wider collaboration and increased citations

- maximum visibility for your research: over $100 \mathrm{M}$ website views per year

At BMC, research is always in progress.

Learn more biomedcentral.com/submissions 